\title{
Establishment success of 25 rare wetland species introduced into restored habitats is best predicted by ecological distance to source habitats
}

\author{
Florence Noël*, Daniel Prati, Mark van Kleunen, Andreas Gygax, Daniel Moser, Markus Fischer \\ Institute of Plant Sciences, University of Bern and Botanical Garden, University of Bern (BOGA), Altenbergrain 21, CH-3013 Bern, Switzerland
}

\begin{abstract}
A B S T R A C T
In response to ongoing local extinction of species and the current biodiversity crisis, the number of reintroduction programs aiming to establish new populations of rare species in the wild has increased. However, only a small proportion of these programs has been planned and monitored scientifically and comparative multi-species studies are missing in this context. Therefore, the relative importance of factors involved in reintroduction success is poorly known. In 2007, we assessed population growth since introduction as a measure of establishment success of 25 wetland species (rare or extinct in the wild nationwide) and a total of 50 populations in Switzerland that had been introduced at seven restored sites with apparently adequate environmental conditions between 1997 and 2005. We related establishment success to 32 life-history traits of these species obtained from the BiolFlor database, to initial number of introduced plants (propagule pressure with 1-130 individuals introduced per population), and to the ecological distance between source sites and restored sites based on vegetation records. Our results clearly showed the importance of close ecological similarity between source and introduction sites for successful establishment of wetland species into restored pond habitats. In contrast, neither life-history traits nor propagule pressure were related to establishment success in our study. Based on our results, we strongly recommend enforcing ecological studies prior to reintroduction to accurately assess the suitability of restored sites. To unambiguously assess the key determinants of successful establishment, future reintroduction programs should be set-up according to experimental designs.
\end{abstract}

\section{Introduction}

Decline and extinction of species are natural phenomena (Levin 2000). However, they have dramatically sped up during the last centuries due to human activities, and resulted in the current biodiversity crisis (Leakey and Lewin, 1995). It has been estimated that currently $13 \%$ of the world's plant species are threatened with extinction (IUCN, 2002), and this percentage is even higher for many local floras. In Switzerland, for example, 32\% of all vascular plant species are listed as threatened in the Red List (Moser et al., 2002). Clearly, mitigating the rate of local species extinction is a major objective of conservation biologists.

It is undisputed that species decline is caused by extrinsic factors such as habitat alteration due to human activities and other components of global change. Therefore, in response to the dramatic loss of plant species, the disciplines of reintroduction biology and restoration ecology have emerged during the last decades

* Corresponding author. Present address: Department of Environmental Sciences, University of Technology Sydney, P.O. Box 123. Broadway, NSW 2007. Australia. Tel.: +61 451024110

E-mail address: Florence.Noel@uts.edu.au (F. Noël).
(Armstrong and Seddon, 2008). Many reintroduction programs have been set-up worldwide with the aim of establishing new populations of rare species in the wild. The success of these programs can now be evaluated. Seddon et al. (2005) recently published an analysis on taxonomic bias in reintroduction projects using records of the International Union for Conservation of Nature (IUCN) reintroduction specialist group. They showed that of the 699 reintroduction projects $30 \%$ concern plant species while $61 \%$ concern vertebrates and only $9 \%$ invertebrates. The apparent underrepresentation of plant-reintroduction projects compared with vertebrates may partly reflect that few results of these projects have been published. For example, in France there have been many plant-reintroduction trials but only four have been published (Bottin et al., 2007 and references therein). In Switzerland, several reintroduction programs of rare plants were carried out, but very few scientific publications have described their results yet (Galeuchet and Holderegger, 2005).

To improve the success rate of projects on reintroduction of rare plant species, we require knowledge on the factors determining establishment success (Pavlik et al., 1993). Therefore, we urgently need to evaluate the success of reintroduction trials. A factor that is likely to contribute to reintroduction success is the number (and 
genetic diversity) of plants introduced at a site. In the literature on invasive alien plants, which might also provide insights into determinants of rarity (Bright and Smithson, 2001; van Kleunen and Richardson, 2007), this introduction effort is better known as propagule pressure, and it has been suggested that this might be the most important determinant of establishment success (Lockwood et al., 2005). If the initial pool of introduced individuals does not have sufficient genetic diversity, the plants may suffer from genetic problems (Colas et al., 1997; Hufford and Mazer, 2003; Kirchner et al., 2006). Indeed, limited genetic diversity is frequently associated with reduced fitness (Leimu et al., 2006), and could result in population extinction.

Other potential determinants of reintroduction success that have not received much attention in conservation biology are intrinsic species traits, such as the capacity for vegetative reproduction and the breeding system (Fischer and Stöcklin, 1997; Murray et al., 2002). Furthermore, extrinsic environmental factors are likely to be important for establishment success (Montalvo and Ellstrand, 2001; Jusaitis, 2005; Bottin et al., 2007; Lawrence and Kaye, 2009). Even among habitats that from an expert-based point of view all look adequate for reintroduction there may be environmental differences important for the long-term success of reintroduction. In addition to absolute habitat quality of a restoration site itself, one might expect that species are most likely to establish in sites that are relatively similar to the source sites of the introduced plants in ecological terms. To the best of our knowledge, however, no study has evaluated yet the roles of introduction effort, intrinsic species traits and the extrinsic environment on establishment success of many rare species in one single study.

Most reintroduction programs focus on a single species, and use only one or a few reintroduction sites. Consequently, it is often impossible to elucidate the determinants of failure or success of such programs. Moreover, none of the few comparative studies with multiple species evaluated the role of intrinsic traits of species on their establishment success (Jusaitis, 2005; Guerrant and Kaye, 2007). We used a unique set-up of experimental reintroduction in the wild of 25 wetland species that are extremely rare or even extinct in the wild in Switzerland. Between 1997 and 2005 these species were introduced at seven restored sites in the Seeland region of Switzerland, where these species used to occur before most of the wetland sites in this region were converted into agricultural land. A total of 50 populations were studied in the field and demographical and ecological surveys were made in 2007. We addressed the following questions: (1) Does the number of introduced plants explain the success of population establishment? (2) Do biological traits of species explain the success of population establishment? (3) Does ecological similarity between source and target habitat explain the success of population establishment? We use the results of our study to make recommendations for future reintroduction projects.

\section{Materials and methods}

\subsection{Introduction history and sites}

The Seeland region, $30 \mathrm{~km}$ west of the city of Bern, used to have many natural wetland habitats. In the last centuries, most of these natural habitats have been converted into cultivated fields, and nowadays the region is a major provider of vegetables. One decade ago, the Swiss Foundation for Landscape Conservation allowed the local association Habitat Network "Grosses Moos" to restore some patches of wetland habitat within this agricultural landscape. At seven locations, ponds, ranging in size between 25 and $1700 \mathrm{~m}^{2}$, were created $500 \mathrm{~m}-5 \mathrm{~km}$ apart from each other (Table 1 ). The sites were created between 1996 and 2002, and then rapidly
Table 1

Compilation of the number of species introduced at each site and the number of species which succeeded $(\log \lambda \geqslant 0)$ or failed $(\log \lambda<0)$ to establish at the site.

\begin{tabular}{lccc}
\hline Site & $\begin{array}{l}\text { Number of } \\
\text { species } \\
\text { introduced }\end{array}$ & $\begin{array}{l}\text { Number of species } \\
\text { successfully } \\
\text { established }\end{array}$ & $\begin{array}{l}\text { Number of species } \\
\text { that failed to } \\
\text { establish }\end{array}$ \\
\hline Baumschulmoos & 1 & 1 & 0 \\
Fräschels & 5 & 4 & 1 \\
Heumoos & 9 & 4 & 5 \\
Krümmi & 11 & 6 & 5 \\
Pré aux Boeufs & 6 & 5 & 1 \\
Staatmoos & 1 & 1 & 0 \\
Stierenbeunden & 17 & 3 & 14 \\
Sum & 50 & 24 & 26 \\
\hline
\end{tabular}

colonized by common wetland species such as Phragmites australis, Juncus effusus and several Carex species. The vegetation was mown annually and removed, thereby repeatedly creating open patches suitable for the establishment of competitively weaker plants.

To further speed up the restoration process, 1-17 rare wetland species were introduced at each site (25 species in total; Table 1 ). The first introductions of six populations were done in 1997, followed by 23 populations in 2000 , five populations in 2001, three populations in 2002, 12 populations in 2004 and one population in 2005. For more than half of the species, the plant material used for introduction was first pre-cultivated in ex-situ populations in the Botanical Garden of Bern. For the other species, individuals were taken directly from natural source populations. Introduction at the restored sites was performed by planting 1-130 (median $=6$ ) individuals either in a limited area in the middle or along the edges of the pond depending on the configuration of the site. One of the two introduced populations of Blackstonia acuminata (the one still existing in 2007) was started from seeds instead of from planted individuals.

\subsection{Study populations and success of establishment}

The reintroduction project included a total of 50 introduced populations (representing 25 species) and 14 sites of still existing source populations (Table 2). To assess the establishment success of the introduced populations, we visited all 50 introduced populations in the summer of 2007. We recorded the sizes of the populations by counting all individuals or by estimating the total number of individuals when the population consisted of $>100$ individuals. For three species (Eleocharis acicularis, Pilularia globulifera and Marsilea quadrifolia) for which the size of the initial population had been estimated as surface cover $\left(\mathrm{m}^{2}\right)$, we also estimated surface cover in 2007. The establishment or demographical success (i) was estimated as.

$\log \lambda \sim\left[\left(\log \left(1+\right.\right.\right.$ popsize $\left.\left._{2007}\right)\right)-\left(\log \left(1+\right.\right.$ popsize $\left.\left.\left._{\text {initial }}\right)\right)\right] /$ year

Here, popsize 2007 is the population size in 2007, popsize initial $_{2}$ is the initial population size at introduction, and year is the number of years since introduction. For the introduced population of B. acuminata started from seed in $2000, \lambda$ was calculated using as initial population size the number of individuals counted at a census in 2004. We added one to census population sizes when estimating $\lambda$ in order to also take loss of populations into account.

\subsection{Vegetation records, ecological distance and biological species traits}

To assess the similarity in habitat conditions of introduced populations and their source populations, we did vegetation records in both types of populations. For the populations still existing in 2007, we recorded all plant species present in an area of $2 \mathrm{~m}^{2}$ around the target species. Nine of the introduced populations were 
Table 2

List of the species of wetland plants studied, total number of introduced populations, number of introduced populations still existing in 2007 during the field survey, and information on whether the source population in the field still existed in 2007 (yes/no).

\begin{tabular}{lllll}
\hline Species name & $\begin{array}{l}\text { Total number of } \\
\text { introduced populations }\end{array}$ & $\begin{array}{l}\text { Number of introduced } \\
\text { populations still existing }\end{array}$ & $\begin{array}{l}\text { Source population } \\
\text { still existing }\end{array}$ & $\begin{array}{l}\text { Total number of populations } \\
\text { studied in the field }\end{array}$ \\
\hline Alisma lanceolatum & 1 & 1 & $\mathrm{y}$ & 2 \\
Anagallis minima & 1 & 0 & $\mathrm{n}$ & 0 \\
Anagallis tenella & 2 & 1 & $\mathrm{n}$ & 1 \\
Apium nodiflorum & 2 & 1 & $\mathrm{n}$ & 1 \\
Apium repens & 3 & 2 & $\mathrm{n}$ & 2 \\
Baldellia ranunculoides & 2 & 1 & $\mathrm{y}$ & 2 \\
Blackstonia acuminata & 2 & 1 & $\mathrm{y}$ & 2 \\
Carex pseudocyperus & 1 & 1 & $\mathrm{y}$ & 2 \\
Eleocharis acicularis & 2 & 1 & $\mathrm{n}$ & 1 \\
Eleocharis ovata & 1 & 1 & $\mathrm{y}$ & 2 \\
Gratiola officinalis & 2 & 1 & $\mathrm{y}$ & 2 \\
Hottonia palustris & 2 & 1 & $\mathrm{n}$ & 2 \\
Iris sibirica & 1 & 1 & $\mathrm{n}$ & 1 \\
Ludwigia palustris & 2 & 1 & $\mathrm{y}$ & 2 \\
Lysimachia thyrsiflora & 1 & 1 & $\mathrm{y}$ & 3 \\
Marsilea quadrifolia & 2 & 2 & $\mathrm{y}$ & 3 \\
Oenanthe fistulosa & 3 & 2 & $\mathrm{y}$ & 3 \\
Oenanthe lachenalii & 3 & 2 & $\mathrm{n}$ & 2 \\
Pilularia globulifera & 4 & 2 & $\mathrm{y}$ & 2 \\
Ranunculus lingua & 2 & 1 & $\mathrm{n}$ & 2 \\
Sium latifolium & 3 & 2 & $\mathrm{n}$ & $\mathrm{y}$ \\
Sparganium emersum & 1 & 1 & $\mathrm{n}$ & $\mathrm{y}$ \\
Teucrium scordium & 2 & 2 & 14 & 2 \\
Typha minima & 2 & 2 & & 2 \\
Viola elatior & 3 & 1 & & 2 \\
Sum & 50 & & & 2 \\
\hline
\end{tabular}

extinct in 2007, and as a consequence we could not do vegetation records around our target species there. However, because these species had been introduced in close proximity to other target species that were still there in 2007, we used the vegetation records of these co-introduced populations as the vegetation records of the extinct populations. This allowed us to also calculate ecological distances between source and introduced populations for some of the introduced populations that had gone extinct by 2007. For all the species in the vegetation records, we compiled the Landolt indicator values for humidity, $\mathrm{pH}$, nutrients, light, temperature, and continentality (Landolt, 1977). The six Landolt indicator values of a species, which are the Swiss equivalent to the more widely used Ellenberg indicator values for the Central European flora (Ellenberg, 1974), indicate the position of the realized niches of the species on an ordinal scale from one to five. For each source and introduced population, we calculated unweighted and weighted averages of each of the six Landolt indicator values (Diekmann, 2003). For the weighted averages, we used the cover of each species, which we had categorized as low, medium and high (1-3) as weight. Because there are many discussions among plant ecologists on whether to use weighted or unweighted ecological indicator indices (Diekmann, 2003), we ran analyses both with weighted and with unweighted Landolt indicator values. Because the results were qualitatively the same, we only present the results for the weighted indicator values. We then performed a Principal Component Analysis (PCA) on the weighted values of the six Landolt indicators. The first two PC axes, represented $>99 \%$ of the variation, and allowed us to discriminate between the source and the introduction sites. Then, site scores on these axes were used to calculate the ecological distance between the source and the introduction sites as the Euclidean distance.

$D=\sqrt{ }\left[\left(P C 1_{1}-P C 1_{S}\right)^{2}+\left(P C 2_{1}-P C 2_{S}\right)^{2}\right]$

Here, $\mathrm{PC} x_{1}$ and $\mathrm{PC} x_{5}$ are the values of the principal component axes for the introduced and source populations, respectively. As a consequence of habitat destruction, some of the source popula- tions had gone extinct. Therefore, the ecological distance to the source population could only be calculated for 27 of the 50 introduced populations, representing 14 of the 25 species.

To test for an effect of biological traits of species on their establishment success, we compiled morphological, reproductive, genetic and ecological traits for all 25 study species from the BiolFlor database (version 1.1, Klotz et al., 2002; see Appendix A for a list of the traits and the values for each species).

\subsection{Statistical analysis}

Because species may not be independent data points as a consequence of a shared evolutionary history (Felsenstein, 1985), we first tested for a phylogenetic signal, and ran Generalized Linear Models (GLMs) in which we accounted for phylogenetic relatedness between the study species. We expressed the phylogeny in the form of principal coordinates using Principal Coordinate Analysis (PCoA) following Desdevises et al. (2003) and also see Küster et al. (2008). We first compiled the phylogenetic distance matrix among the species by calculating the pair-wise distance between species from the phylogenetic tree based on the phylogenetic codes as given in the BiolFlor database (Klotz et al., 2002). The phylogenetic codes of Apium repens, Apium nodiflorum and Sium latifolium in BiolFlor indicated that $A$. nodiflorum branches more closely with $S$. latifolium than with $A$. repens. Others have, however, shown that the phylogenetic structure of this group is [(Sium, Oenanthe), Apium] (Downie et al., 2000; Calviño et al., 2006). Therefore, we decided to perform the analyses with the phylogenetic distance matrix according to BiolFlor, and a corrected matrix in which the two Apium species branch together in the group with the Sium species and the Oenanthe species. Because the results based on the two phylogenetic distance matrices were very similar, we only present results for the corrected matrix. We did a PCOA on the phylogenetic distance matrix, and retained the first four PCo axes that cumulatively accounted for $80 \%$ of the phylogenetic variation for inclusion in phylogenetically informed GLMs (see below). 

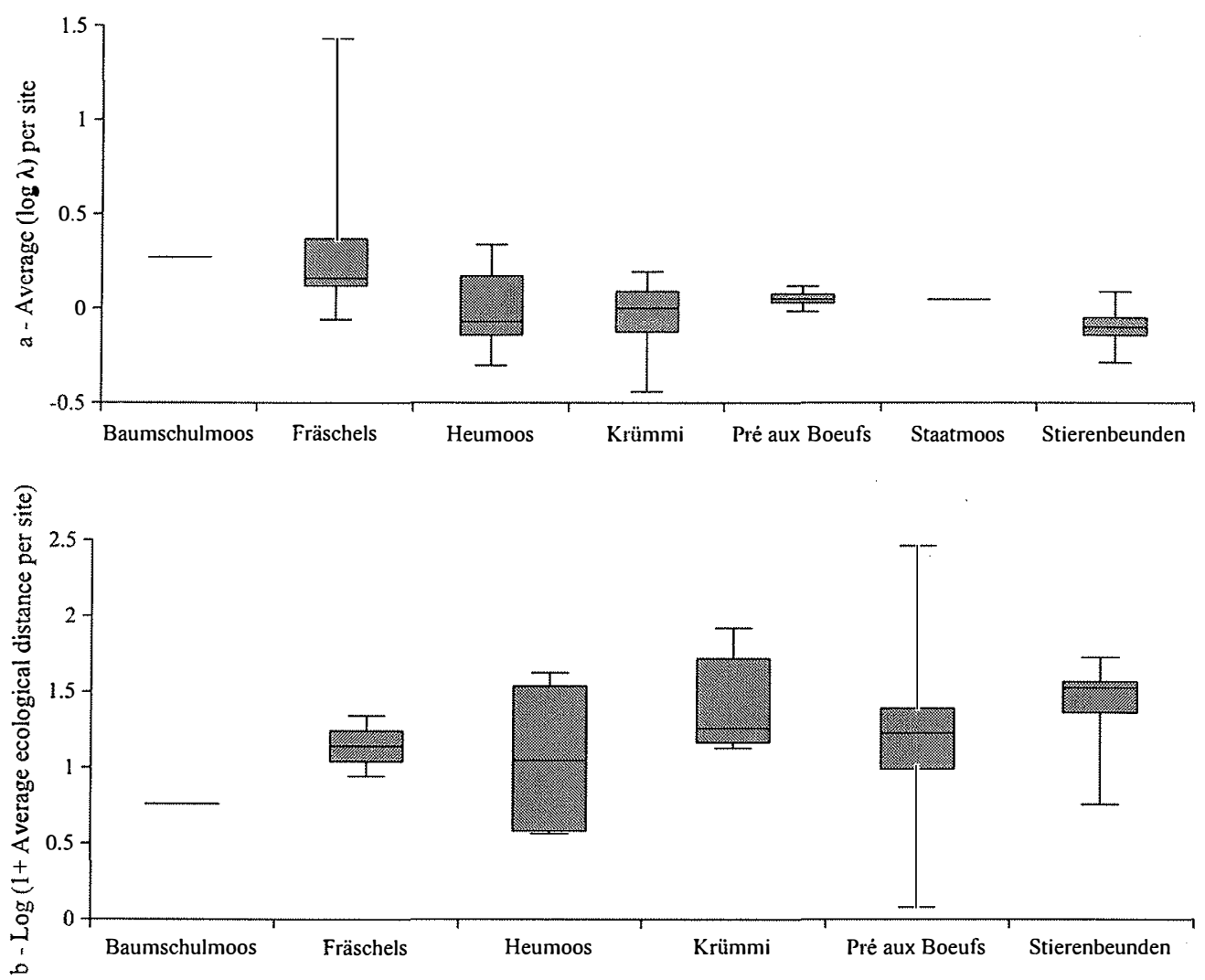

Fig. 1. (a) Mean establishment success $(\log i)$ of 50 populations from 25 reintroduced wetland species at seven sites in Switzerland. (b) Log ( $1+$ average ecological distance) based on vegetation records between source and introduced sites of 14 of the reintroduced wetland species. Significant differences among sites were detected for (log $\lambda$ ) only.

To test whether establishment success $(\log \lambda)$ of introduced populations varied among sites and whether it was associated with number of introduced plants, pre-cultivation in the Botanical Garden, ecological distance to source populations and the 32 biological species traits, we first ran GLMs for each variable separately. Then to account for phylogeny, we also included the four first PCo axes based on the phylogenetic distance matrix as covariables in the GLMs. Finally, we ran multiple regression GLMs including only the variables that were significant in the single-variable GLMs and the four first PCo axes based on the phylogenetic distance matrix.

All statistical analyses were performed with $R$ ( $R$ Development Core Team, 2008, version 2.8.1). If necessary, continuous variables were In-transformed to improve linearity in the regression analysis.

\section{Results}

Twenty-one of the 50 introduced populations had increased in size $(\log \lambda>0)$, three populations had remained stable $(\log i=0)$. eight populations were still present but had declined in size $(\log i<0)$, and 18 populations had gone extinct. The proportion of successfully established populations with $\log \lambda \geqslant 0$ per site ranged from 0.176 to 1 (Table 1 ). The average proportion of successfully established populations per species was $0.68 \pm 0.28$, and five species (eight populations in total) failed to establish at any restored site while seven species (10 populations in total) had established successfully at all restored sites where they had been introduced. The average establishment success of introduced populations varied significantly among the seven restored sites $\left(F_{6.43}=3.22, p=0.01\right.$; Fig. $1 \mathrm{a}$, Table $\left.3 \mathrm{a}\right)$, but did not depend on the number of individuals that had been introduced $\left(F_{1,48}=1.32\right.$, $p=0.25$ ) or on whether they had first been pre-cultivated in the Botanical Garden prior to introduction in the restored site $\left(F_{1,48}=0.81, p=0.37\right)$.

The two-square meter vegetation records in the source populations and the introduced populations revealed a total of 138 plant species co-occurring with our introduced study species. The three most common co-occurring species were $P$. australis, Lysimachia vulgaris and Lythrum salicaria. The ecological distance between the source and introduced population was not significantly different among introduction sites $\left(F_{5,21}=0.534, p=0.748\right.$; Fig. $\left.1 \mathrm{~b}\right)$. Establishment success of introduced populations was significantly negatively correlated with ecological distance between the source and introduced population (Pearson's $r=-0.40, p=0.037, d f=25$; Fig. 2, Table 3a). This indicates that introduced populations were more likely to successfully establish if the habitat at the site of introduction was more similar to the habitat of the source population.

Of the 32 species traits considered (Appendix A) none had a significant effect on establishment success. Phylogeny explained a significant proportion of the variation in establishment success (Table 3a). However, all effects that were significant in unifactorial models (i.e. site of introduction and, ecological distance between source and introduced habitats) remained significant when accounting for phylogeny (Table $3 a$ ). In the multifactorial model, including the terms that were significant in unifactorial analyses, only the negative effect of ecological distance between source and introduced habitats on establishment success remained significant (Table $3 \mathrm{~b}$ ). This indicates that ecological distance between the source and introduced habitat is the main determinant of establishment success. 
Table 3

(a) Results of unifactorial general linear models with or without the PCos used as covariables to account for phylogeny. For each trait, the percentage of variance in establishment success $(\log \lambda)$ explained by the model are given. The model with only the PCos is given. (b) Results of the multifactorial model with PCos as covariables.

\begin{tabular}{|c|c|c|c|c|c|c|}
\hline Variables & $d f$ (effect, residuals) & Sum Sq. & Mean Sq. & $F$ & $P$ & $R^{2}$ \\
\hline \multicolumn{7}{|l|}{ (a) Unifactorial models } \\
\hline Introduction site & 6.43 & 1.027 & 0.171 & 3.224 & 0.01 & 0.31 \\
\hline Ecological distance & 1.25 & 0.104 & 0.104 & 4.934 & 0.036 & 0.165 \\
\hline \multicolumn{7}{|l|}{ Model with phylogeny only } \\
\hline PCo1 & 1.45 & 0.241 & 0.241 & 3.887 & 0.055 & 0.158 \\
\hline $\mathrm{PCO} 2$ & 1.45 & 0.171 & 0.171 & 2.763 & 0.103 & \\
\hline $\mathrm{PCo} 3$ & 1.45 & 0.03 & 0.03 & 0.485 & 0.49 & \\
\hline PCo4 & 1.45 & 0.083 & 0.083 & 1.338 & 0.253 & \\
\hline \multicolumn{7}{|l|}{ Model with traits + phylogeny } \\
\hline Introduction site $+\mathrm{PCo}+\mathrm{PC} 22+\mathrm{PC}_{3}+\mathrm{PC}_{4}$ & 6.39 & 1.027 & 0.171 & 3.388 & 0.009 & 0.405 \\
\hline Ecological distance $+\mathrm{PCo} 1+\mathrm{PC} 02+\mathrm{PC} 03+\mathrm{PC}_{4}$ & 1.21 & 0.104 & 0.104 & 5.272 & 0.032 & 0.343 \\
\hline \multicolumn{7}{|l|}{ (b) Multifactorial model } \\
\hline Variables & $d f$ & Sum Sq. & Mean Sq. & $F$ & $p$ & $R^{2}$ \\
\hline Ecological distance & 1 & 0.104 & 0.104 & 5.830 & 0.028 & 0.547 \\
\hline Introduction site & 5 & 0.155 & 0.031 & 1.731 & 0.185 & \\
\hline PCo1 & 1 & 0.018 & 0.018 & 0.994 & 0.333 & \\
\hline $\mathrm{PCO} 2$ & 1 & 0.000 & 0.000 & 0.011 & 0.918 & \\
\hline $\mathrm{PCO} 3$ & 1 & 0.026 & 0.026 & 1.459 & 0.245 & \\
\hline PCo4 & 1 & 0.433 & 0.043 & 2.417 & 0.14 & \\
\hline Residuals & 16 & 0.286 & 0.018 & & & \\
\hline Model description & $R^{2}$ & & & & & \\
\hline $\mathrm{PC} 01+\mathrm{PC}_{02}+\mathrm{PCO}_{3}+\mathrm{PCO}_{4}$ & 0.158 & & & & & \\
\hline Ecological distance + introduction site & 0.410 & & & & & \\
\hline Ecological distance $*$ introduction site & 0.575 & & & & & \\
\hline Ecological distance $*$ introduction site $+\mathrm{PCol}+\mathrm{PCO} 2+\mathrm{PC} 03+\mathrm{PCO}_{4}$ & 0.734 & & & & & \\
\hline
\end{tabular}

\section{Discussion}

Our evaluation of a project on reintroduction of 25 rare wetland species into restored pond habitats in Switzerland showed that establishment success of these species is mainly determined by similarity of ecological conditions in the source and introduced populations. On the other hand, the number of plants introduced per population and biological species traits did not appear to affect establishment success of our study species. These results were robust with respect to considering phylogenetic relatedness among species.

\subsection{Ecological similarity is the key factor for establishment success}

The mean establishment success of populations was $48 \%$ ( 24 successful populations out of 50). In the literature, no similar study involving only rare plant species and seedlings transplants exists. However several papers have reviewed and discussed the estab-

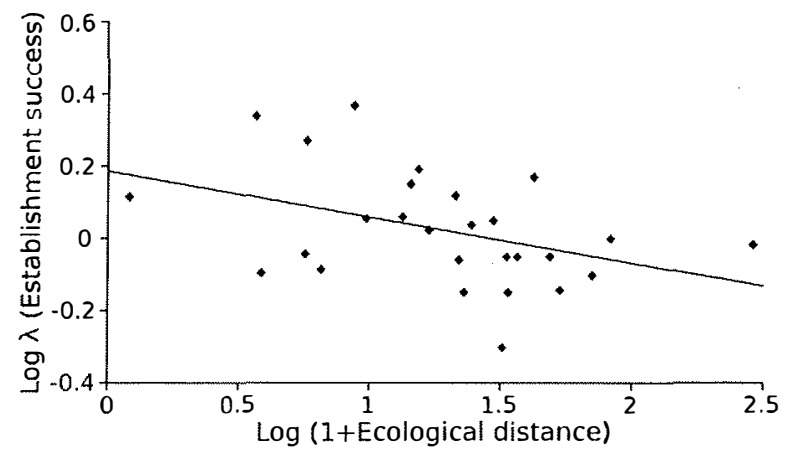

Fig. 2. The relationship between establishment success $(\log i)$ and the ecological distance between source and introduced sites of 27 populations of 14 reintroduced wetland species in Switzerland. lishment success of grassland restoration programs and showed either similar or higher establishment success (Hedberg and Kotowski, 2010; Kiehl et al., 2010). The lowest establishment success observed here could be explained by the fact that these restoration programs usually involve common species which may not suffer from survival threats such as reduced genetic diversity.

Our results showed significant variation in establishment success of introduced populations among the seven introduction sites. The variation in establishment success among sites remained significant when accounting for phylogenetic relatedness of the study species (Table 3a), which suggests that variation among sites was not due to differences in the sets of species introduced at each site.

Possibly, variation in establishment success among sites could reflect differences in management of the sites and degree of colonization by common species, such as P. australis, J. effusus and Carex species. Moreover, it is possible that differences in interspecific competition explain some of the differences in establishment success among sites (Jusaitis, 2005; Fahselt, 2007).

Variation in establishment success among sites may also partly reflect variation in ecological distance between source and introduction sites. However, variation among restored sites in their ecological distance to the source sites was not significant. Nevertheless, the site with the highest average establishment success (site of Fräschels; $0.40 \pm 0.35$ ) had a low average ecological distance to the source sites $(2.19 \pm 0.81)$, while the site with the lowest average establishment success (site of Stierenbeunden; $-0.08 \pm 0.01)$ had a high average ecological distance to the source sites $(3.18 \pm 1.53)$. Indeed, the results of the multifactorial model showed that ecological distance between introduction and source sites was the only factor that remained significant for establishment success of the populations (Table $3 \mathrm{~b}$ ).

So, ecological distance between source and introduced populations appeared to be the main factor explaining establishment success of the study species. This result extends the findings of other studies on restoration of sites or reintroduction of plants which have shown a major importance of habitat quality on 
establishment success (Jusaitis, 2005; Bottin et al., 2007; Fahselt, 2007; Lawrence and Kaye, 2009) and that the ecological distance was a good predictor for plant establishment (Montalvo and Ellstrand, 2000; Bischoff et al., 2006; Raabova et al., 2007). However, while these previous studies were done for single or very few species, our study is the first one showing that the importance of ecological distance is a general pattern across a large number of species and that ecological distance matters even for reintroduction sites that all had appeared suitable based on expert-opinion at the time of introduction. It is also the first study testing for the impact of ecological, biological (i.e. life-history traits) and demographical factors on establishment success at the same time. Therefore, it allowed us to discriminate among most of the potential factors influencing establishment success.

\subsection{Initial introduction effort is not related to establishment success}

Our results showed that the initial number of individuals introduced at restored sites did not have a significant impact on the establishment success of populations. In other words, this indicates that introduction effort (or propagule pressure) did not appear as a key determinant of establishment success in our study. This result is inconsistent with the general expectation that the more founders you have, the greater will be the chance of establishment success (Falk et al., 1996; Guerrant, 1996; Montalvo et al., 1997; Guerrant and Kaye, 2007). One potential reason for the absence of an introduction-effort effect in our study is that the maximum number of introduced individuals was still relatively small (130 individuals). Furthermore, in our study, genetic diversity of founders and consequently effective population sizes were not known, although this could greatly affect establishment success (Leberg, 1993; Newman and Pilson, 1997; Prati et al., unpublished data). Because all individuals introduced at the restored sites came from source populations that were themselves already reduced to small sizes, genetic variability within the source population could have been very low (Ellstrand and Elam, 1993; Lynch et al., 1995; Young et al., 1996; Fischer et al., 2000). Such an explanation is also supported by the non-significant effect of the pre-cultivation at the Botanical Garden prior to introduction that could have been seen as a potential bottleneck effect. Therefore, it is likely that introduction of more individuals did not result in introduction of much more genetic diversity. Consequently, it is likely that all populations, irrespective of their size, may have suffered from demographic stochasticity and genetic problems to a similar extent (Montalvo and Ellstrand, 2001; Krauss et al., 2002; Colas et al., 1997; Kirchner et al., 2006). Finally, variation in introduction-effort thresholds for population establishment among species could have obscured a potential impact of a general introduction effort in our study.

\subsection{Intrinsic species traits are not related to establishment success}

Although phylogeny had a significant effect on establishment success, our results showed that none of the biological species traits tested had a significant impact on establishment success (Table 3a). Previous studies had considered species traits as potentially important factors influencing the establishment success (Hamrick and Godt, 1989; Hamrick et al., 1992; Montalvo et al., 1997) and persistence (Fischer and Stöcklin, 1997). Moreover, studies on invasiveness of alien species also indicate that species traits may be important determinants of establishment success (Pyšek and Richardson, 2007; Schlaepfer et al., 2010; van Kleunen et al., 2010). A potential reason for the lack of significant effects of species traits on establishment success of the wetland species considered in our study could be that species were similar to each other in most traits, and all of them are rare species that might share potential rarity traits. Consequently, there was limited statistical power. For instance, we expected a positive effect of the ability of vegetative reproduction, but only four of the 25 study species are lacking the capacity for vegetative reproduction. Furthermore, the species traits were restricted to relatively simple ones that were available from databases. This means that we did not have data on potentially relevant traits such as environmental tolerance and competitive ability of the species. Therefore, future studies should include species that cover more variation in traits, and these studies should also experimentally assess potentially important traits that are not available in databases.

\section{Conclusions}

It is obvious that wetland species can only successfully establish in wetlands. Our results showed that the creation of pond habitats is not sufficient to warrant successful population establishment of endangered wetland plants, but that the latter requires that the reintroduction and source sites are ecologically very similar. Because reintroduction programs are frequently set-up under tight deadlines, specific biotic and abiotic requirements of the species are usually not well investigated, and the suitability of the reintroduction sites are poorly evaluated (see Fahselt, 2007). Therefore, we strongly recommend supporting future reintroductions only based on good information on ecological requirements of the involved species and of the habitat conditions at potential target sites. Comparative study of ecological factors in sites still occupied by the species and sites were the species went extinct constitutes a powerful approach (Ren et al., 2010). This is particularly important and challenging in the case of introducing multiple species at the same site, where such environmental information on source and target sites allows and requires identifying suitable multi-species assemblages of source plant material prior to introduction.

Finally, this study also demonstrated that intermediate cultivation in botanical gardens is an important step in ex-situ conservation. Among the 25 species studied, seven have been introduced at restored sites from botanical garden populations while the source populations in the field had gone extinct. Generally, even though we did not find a significant effect of introduction effort in our study, inclusion of sufficient genetic diversity by introducing plant material from different populations can be an important factor for establishment success (Falk and Holsinger, 1991; Hufford and Mazer, 2003). In some cases, ex-situ populations in botanical gardens may become the only available source of genetic diversity for species re-establishment programs. Therefore, founding botanical garden populations of high genetic diversity is a vital measure to enable future reintroduction of endangered species into nature. Ideally, as reintroduction success may be highest with local seed material (Vander Mijnsbrugge et al., 2010), plants from several source populations should be kept ex-situ in botanical gardens.

Although we included several potential factors that could explain establishment success, there are further factors, such as further species traits, genetic factors or ecological habitat characteristics, whose effects have not been tested empirically yet. Furthermore, few studies have tried to evaluate the impacts of ecological variables on specific life-cycle stages to determine the key-stage for restoration (Maschinski and Duquesnel, 2006), and consequently, it is still largely unknown which specific stages are important in the restoration process. In general, for further progress in restoration ecology, we urgently need more reintroduction trials explicitly set-up as scientific experiment testing for the contributions of several interacting factors to restoration success. 


\section{Acknowledgements}

We thank the staff of the Botanical Garden in Bern for growing some of the plant material prior to introduction. MF and MvK thank the National Centre of Competence in Research - Plant Survival for funding. We would also like to thank Prof. N. Machon and two anonymous reviewers for their valuable comments on this manuscript.

\section{Appendix A. Supplementary material}

Supplementary data associated with this article can be found, in the online version, at doi:10.1016/j.biocon.2010.11.001.

\section{References}

Armstrong, D.P., Seddon, P.J., 2008. Directions in re-introduction biology. Trends in Ecology and Evolution 23, 20-25

Bischoff, A., Cremieux, L., Smilauerova, M., Lawson, C.S., Mortimer, S.R., Dolezal, J., Lanta, V., Edwards, A.R., Brook, A.J., Macel, M., 2006. Detecting local adaptation in widespread grassland species - the importance of scale and local plant community. Journal of Ecology 94, 1130-1142.

Bottin, L., Le Cadre, S., Quilichini, A., Bardin, P., Moret, J., Machon, N., 2007. Reestablishment trials in endangered plants: a review and the example of Arenaria grandiflora, a species on the brink of extinction in the Parisian region (France). Ecoscience 14, 410-419.

Bright, P.W.. Smithson. T.J., 2001. Biological invasions provide a framework for reintroductions: selecting areas in England for pine marten releases. Biodiversity and Conservation 10, 1247-1265.

Calviño, C.I., Tilney, P.M., van Wyk, B.-E., Downie, S.R., 2006. A molecular phylogenetic study of southern African Apiaceae. American Journal of Botany 93, 1828-1847.

Colas, B., Olivieri, I., Riba, M., 1997. Centaurea corymbosa, a cliffdwelling species tottering on the brink of extinction: a demographic and genetic study. Proceedings of the National Academy of Sciences 94, 3471-3476.

Desdevises, Y., Legendre, P., Azouzi, L., Morand, S., 2003. Quantifying phylogenetically structured environmental variation. Evolution 57, 26472652.

Diekmann, M., 2003. Species indicator values as an important tool in applied plant ecology - a review. Basic Applied Ecology 4, 493-506.

Downie, S.R., Katz-Downie, D.S., Watson, M.F., 2000. A phylogeny of the flowering plant family Apiaceae based on chloroplast DNA RPL16 and RPOC1 intron sequences: towards a suprageneric classification of subfamily Apioideae. American Journal of Botany 87, 273-292.

Ellenberg, H., 1974. Zeigerwete der Gefässpflanzen M it-teleuropas. Scripta Geobotanica 9, 1-97.

Ellstrand, N.C., Elam, D.R., 1993. Population genetic consequences of small population size: implications for plant conservation. Annual Review of Ecology and Systematics 24, 217-242.

Fahselt, D., 2007. Is transplanting a effective means of preserving vegetation? Canadian Journal of Botany 87, 1007-1017.

Falk,. D.A., Holsinger, K.E., 1991. Genetics and Conservation of Rare Plants. Oxford University Press, New York.

Falk, D.A., Millar, C.I., Olwell, M., 1996. Restoring Diversity. Island Press, Washington, DC.

Felsenstein. J. 1985. Phylogenies and the comparative methods. The American Naturalist 125, 1-15.

Fischer, M., Stöcklin, J., 1997. Local extinctions of plants in remnants of extensively used calcareous grasslands 1950-1985. Conservation Biology 11, 727-737.

Fischer, M., Husi, R., Prati, D., Peintinger, M., van Kleunen, M., Schmid, B., 2000. RAPD variation among and within small and large populations of the rare clonal plant Ranunculus reptans (Ranunculaceae). American Journal of Botany 87 . 1128-1137.

Galeuchet, D.J., Holderegger, R., 2005. Erhaltung und Wiederansiedlung des Kleinen Rohr-kolbens (Typha minima) - Vegetationsaufnahmen, Monitoring und genetische Herkunftsanalysen. Botanica Helvetica 115, 15-32.

Guerrant, E.O., 1996. Designing populations: demographic, genetic and horticultural dimensions. In: Falk, D.A., Millar, C.I., Olwell, M. (Eds.), Restoring Diversity: Strategies for Reintroduction of Endangered Plants. Island Press, Washington, DC, pp. 171-208

Guerrant, E.O., Kaye, T.N., 2007. Reintroduction of rare and endangered plants: common factors, questions, and approaches. Australian Journal of Botany 55 362-370.

Hamrick, J.M., Godt, J.M.W., 1989. Allozyme diversity in plant species. In: Brown, A.H.D., Clegg, M.T., Kahler, A.L., Weir, B.S. (Eds.), Plant Population Genetics, Breeding and Germplasm Resources. Sinauer, Sunderland, pp. 43-63.

Hamrick, J.L., Godt, M.J.W., Sherman-Broyles, S.L., 1992. Factors influencing levels of genetic diversity in woody plant species. New Forests 6, 95-124.

Hedberg, P.. Kotowski, W., 2010. New nature by sowing? The current state of species introduction in grassland restoration and the road ahead. Journal of Nature Conservation 18, 304-308.
Hufford, K.M., Mazer, S.J., 2003. Plant ecotypes: genetic differentiation in the age of ecological restoration. Trends in Ecology and Evolution 18, 147155

IUCN, 2002. Thorny Issues for the World's Plants: How Much Do We Really Know? Report of 06/11/2002.

Jusaitis, M., 2005. Translocation trials confirm specific factors affecting the establishment of three endangered plant species. Ecological Management \& Restoration 6, 61-67.

Kiehl, K., Kirmer, A., Donath, T.W., Rasran, L., Hölzel, N., 2010. Species introduction in restoration projects - evaluation of different techniques for the establishment of semi-natural grassland in Central and Northwestern Europe. Basic and Applied Ecology 11, 285-299.

Kirchner. F., Fréville, H., Olivieri, I., Riba, M., Colas, B., 2006. Apports d'une expérience d'introduction de populations menée 10 ans chez Centaurea corymbosa. Congress: Le réveil du dodo 2006, Paris.

Klotz, S., Kühn, I., Durka, W., 2002. Eine Datenbank zu biologisch-ökologischen Merkmalen der Gefäßpflanzen in Deutschland. Schriftenreihe für Vegetationskunde 38. Bundesamt für Naturschutz, Bonn

Krauss, S.L., Dixon, B., Dixon, K.W., 2002. Rapid genetic decline in a translocated population of the endangered plant Grevillea scapigera. Conservation Biology 16 986-994.

Küster, E.C., Kühn, I., Bruelheide, H., Klotz, S., 2008. Trait interactions help explain plant invasion success in the German flora. Journal of Ecology 96, 860-868.

Landolt, E., 1977. Ökologische Zeigerwerte zur Schweizer Flora: Veröffentlichungen des Geobotanischen Instituts. Stiftung Rübel 64, 1-208.

Lawrence, B.A., Kaye, T.N., 2009. Reintroduction of Castilleja levisecta: effects of ecological similarity, source population genetics, and habitat quality. Restoration Ecology. doi:10.1111/j.1526-100X.2009.00549.x.

Leakey, R., Lewin, R., 1995. The Sixth Extinction: Patterns of Life and the Future of Humankind. Anchor Books Doubleday, New-York.

Leberg, P.L., 1993. Strategies for population reintroduction: effects of genetic variability on population growth and size. Conservation Biology 7, 194199.

Leimu, R., Mutikainen, P., Koricheva, J., Fischer, M., 2006. How general are positive relationships between plant population size, fitness and genetic variation? Journal of Ecology 94, 942-952.

Levin, D.A., 2000. The Origin, Expansion, and Demise of Plant Species. Oxford University Press, New York.

Lockwood, J.L., Cassey, P., Blackburn, T., 2005. The role of propagule pressure in explaining species invasions. Trends in Ecology and Evolution 20, 223228.

Lynch, M., Conery. J., Bürger, R., 1995. Mutation accumulation and the extinction of small populations. American Naturalist 146, 489-518.

Maschinski. J.. Duquesnel. J., 2006. Successful re-introductions of the endangered long-lived Sargent's cherry palm, Pseudophoenix sargentii, in the Florida Keys. Biological Conservation 134, 122-129.

Montalvo, A.M., Ellstrand, N.C., 2000. Transplantation of the subshrub Lotus scoparius: testing the home-site advantage hypothesis. Conservation Biology 14, 1034-1045.

Montalvo, A.M., Ellstrand, N.C., 2001. Population biology-nonlocal transplantation and outbreeding depression in the subshrub Lotus scoparius (Fabaceae). American Journal of Botany 88, 258-269.

Montalvo, A.M., Williams, S.L., Rice, K.J., Buchmann, S.L., Cory, C., Handel, S.N., Nabhan, G.P., Primack, R., Robichaux, R.H., 1997. Restoration biology: a population biology perspective. Restoration Ecology 5, 277-290.

Moser, D., Gygax, A., Bäumler, B., Wyler, N., Palese, R., 2002. Liste rouge des espèces menacées de Suisse: Fougères et plantes à fleur. Office fédéral de l'environnement, des forêts et du paysage, Switzerland (OFEFP, Berne).

Murray, B., Thrall, P.H., Gill, A.M., Nicotra, A.B., 2002. How plant life-history and ecological traits relate to species rarity and commonness at varying spatial scales. Austral Ecology 27, 291-310.

Newman, D., Pilson, D., 1997. Increased probability of extinction due to decreased genetic effective population size: experimental populations of Clarkia pulchella. Evolution 51, 354-362

Pavlik, B.M., Nickrent, D.L., Howald, A.H., 1993. The recovery of an endangered plant. I. Creating a new population of Amsinckia grandiflora. Conservation Biology 7, 510-526.

Pyšek, P., Richardson, D.M. 2007. Traits associated with invasiveness in alien plants: where do we stand? In: Nentwig. W. (Ed.), Biological Invasions. Ecological Studies, vol. 193. Springer-Verlag, Berlin, pp. 97-126.

R Development Core Team, 2008. R: A Language and Environment for Statistical Computing. R Foundation for Statistical Computing, Vienna, Austria. ISBN:3900051-07-0. <http://www.R-project.org>.

Raabova, J., Munzbergova, Z. Fischer. M. 2007. Ecological rather than geographic or genetic distance affects local adaptation of the rare perennial herb. Aster amellus. Biological Conservation 139, 348-357.

Ren, H., Zhqng, Q., Wang, Z., Guo, Q., Wang, J., Liu, N., Liang, K., 2010 Conservation and Possible Reintroduction of an Endangered Plant Based on an Analysis of Community Ecology: A Case Study of Primulina tabacum Hance in China.

Schlaepfer, D.R., Glättli, M., Fischer, M., van Kleunen, M., 2010. A multi-species experiment in their native range indicates pre-adaptation of invasive alien plant species. New Phytologist 185, 1087-1099.

Seddon, P.J., Soorae, P.S., Launay, F., 2005. Taxonomic bias in re-introduction projects. Animal Conservation 8, 51-58. 
van Kleunen, M., Richardson, D.M., 2007. Invasion biology and conservation biology: time to join forces to explore the links between species traits and extinction risk and invasiveness. Progress in Physical Geography 31, 447-450. van Kleunen. M., Weber, E., Fischer, M., 2010. A meta-analysis of trait differences between invasive and non-invasive plant species. Ecology Letters 13. 235-245.
Vander Mijnsbrugge, K.. Bischoff, A., Smith. B., 2010. A question of origin: where and how to collect seed for ecological restoration. Basic and Applied Ecology 11. 300-311.

Young, A., Boyle, T., Brown. T., 1996. The population genetic consequences of habitat fragmentation. Trends in Ecology and Evolution 11, 413-418. 